\title{
Chemosensitivity and role of swimming legs of mud crab, Scylla paramamosain, in feeding activity as determined by electrocardiographic and behavioural observations
}

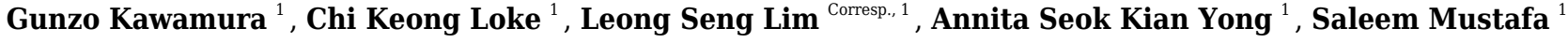 \\ ${ }^{1}$ Borneo Marine Research Institute, Universiti Malaysia Sabah, Kota Kinabalu, Sabah, Malaysia \\ Corresponding Author: Leong Seng Lim \\ Email address: leongsen@ums.edu.my
}

Swimming crabs have a characteristic fifth pair of legs that are flattened into paddles for swimming purposes. The dactyl of these legs bears a thick seta along its edge. The chemoreceptive and feeding properties of the seta are supported with scientific evidence, however, there is no available data on the sensitivity of the setae in portunid crabs. The underlying mechanisms of the chemo- and mechano-sensitivity of appendages and their involvement in feeding activities of the mud crab (Scylla paramamosain) were investigated using electrocardiography and behavioural assay, which focused on the responses of the mud crab to chemical and touch stimulus. Electrocardiography revealed the sensory properties of the appendages. The dactyls of swimming legs and the antennules were chemosensitive, but not mechanosensitive and vice versa for the antennae. However, the mouthparts, claws, and walking legs were chemo- and mechanosensitive. Only the chemosensitive appendages, including the swimming legs, were directly involved in feeding. The flattened dactyls of the swimming legs were more efficient than the pointed dactyls of the walking legs in detecting the food organism crawling on the substrate. The structural features enhanced the capacity of the crab in coming into contact with scattered food items. This study revealed that the swimming legs are important appendages for feeding in the mud crab. 


\section{PeerJ}

2 Original Paper

3

4 Chemosensitivity and role of swimming legs of mud crab, Scylla paramamosain, in feeding 5 activity as determined by electrocardiographic and behavioural observations

7 Gunzo Kawamura ${ }^{1}$, Chi Keong Loke ${ }^{1}$, Leong-Seng Lim ${ }^{1, *}$, Annita Seok Kian Yong ${ }^{1}$ and

8 Saleem Mustafa ${ }^{1}$

${ }^{1}$ Borneo Marine Research Institute, Universiti Malaysia Sabah, 88400 Kota Kinabalu, Sabah,

11 Malaysia

12

$\bowtie \square$ Leong-Seng Lim

E-mail: leongsen@ums.edu.my

\section{ABSTRACT}

Swimming crabs have a characteristic fifth pair of legs that are flattened into paddles for swimming purposes. The dactyl of these legs bears a thick seta along its edge. The chemoreceptive and feeding properties of the seta are supported with scientific evidence, however, there is no available data on the sensitivity of the setae in portunid crabs. The underlying mechanisms of the chemoand mechano-sensitivity of appendages and their involvement in feeding activities of the mud crab (Scylla paramamosain) were investigated using electrocardiography and behavioural assay, which focused on the responses of the mud crab to chemical and touch stimulus. Electrocardiography revealed the sensory properties of the appendages. The dactyls of swimming legs and the antennules were chemosensitive, but not mechanosensitive and vice versa for the antennae. However, the mouthparts, claws, and walking legs were chemo- and mechanosensitive. Only the chemosensitive appendages, including the swimming legs, were directly involved in feeding. The flattened dactyls of the swimming legs were more efficient than the pointed dactyls of the walking 
30

31

32

33

34

35

36

37

38

capacity of the crab in coming into contact with scattered food items. This study revealed that the swimming legs are important appendages for feeding in the mud crab.

\section{Keywords}

Feeding appendages, ECG, Sensory system, Antenna, Antennule, Mud crab

\section{INTRODUCTION}

Mud crabs, Scylla spp., are distributed in estuarine, sheltered coastal habitats, and mangroves in the Indo-Pacific region and South Africa (Ikhwanuddin et al., 2011; Alberts-Hubatsch et al., 2016). Four commercially important Scylla species (S. serrata, S. olivacea, S. paramamosain, and $S$. tranquebarica) live in the same geographical area in Malaysia (Alberts-Hubatsh et al., 2016) and are often captured in the same traps (Kawamura et al., 2021). In the wild population, inter-species mating has also been reported (Fazhan et al., 2020).

In crustaceans, all the appendages and several body parts are responsible for chemoreception (Ache, 1982). The most important chemosensory structures include the antennae, antennules (first antennae), walking legs, and mouthparts (Schmidt \& Mellon, 2011). Several investigations have been conducted on lobsters (Nishida et al., 1990; Gomez \& Atema, 1996; Garm \& Høeg, 2000; Garm 2004a; Garm et al., 2005; Sahlmann, Chan \& Chan, 2011), crayfish (Dunham \& Oh 1992; Garm, 2004b; Mellon, 2012), hermit crab (Garm 2004a; Kamio et al., 2005), and blue crab Callinectes sapidus (Gleeson, Adams \& Smith, 1984; Keller, Powell \& Weissburg, 2003; Aggio et al., 2012). Nevertheless, S. serrata has been studied for the chemosensory function of its appendages amongst the Scylla spp. (Wall, Paterson \& Mohan, 2009).

\section{4}

Decapod crustaceans possess setae on many parts of their appendages (Ache, 1982). To understand the behaviour of decapod crustaceans in the wild and under culture environments, it is important to study the sensory function of the appendages and their role in feeding and social communication. The setae could either be sensory or non-sensory. The former includes chemoreception or mechanoreception, which are determined using either one or a combination of behavioural, physiological, and morphological analysis. For studies based on behavioural 
61

62 63

64

65

66

67

68

69

70

71

72

73

74

75

76

77

78

79

80

81

82

83

84

85

86

87

88

89

90

91

assessment, an animal may have the capacity to perceive a stimulus, but it does not always lead to a change in response (Nishi \& Kawamura, 2005). Physiological-based studies are limited as a result of non-detection of neural response, especially when the receptor's size is either small or labile (Kawamura, 1981; Jordão, Cronin \& Oliveira, 2007), and when receptor potentials are unstable (Kawamura et al., 2020). The availability of different morphological types of setae among the decapod species makes the method uncertain while morphological analysis of setae provides a better understanding of the structures and functions (Garm, 2004b).

68

9

Electrocardiography is a reliable method of detecting the sensitivity of an animal to external stimuli (Kawamura, Nakaizumi \& Motohiro, 1992; Nishi, Kawamura \& Matsumoto, 2004; Nishi \& Kawamura, 2005). In the tetrapods, the heart pacemaker is innervated by the excitatory sympathetic nervous system and the inhibitory parasympathetic nerve. However, in the heart of teleosts, the parasympathetic vagus nerve is the sole regulator of heart rate. Activation of the vagus nerve results in the release of acetylcholine - a neurotransmitter substance that acts via muscarinic receptors to influence the force and rate of contraction of the heart muscles. During resting or inactivity, inhibitory vagal stimulation on the heart is absent (Taylor et al., 2007). Fishes and crustaceans show a typical electrocardiogram response, slower heartbeat, or wider interbeat interval, in response to external stimuli. Electrocardiography has been applied to examine the response of crab species to temperature, pressure (Mickel \& Childress, 1982), visual stimulus (Grober, 1990; Hermitte \& Maldonado, 2006; Burnovicz, Oliva \& Hermitte, 2009; Burnovicz \& Hermitte, 2010), and chemical stimulus (Ketpadung \& Tangkrockolan, 2006; Medesani et al., 2011).

Mud crab (family Portunidae) is distinguished from other crabs by the structural adaptation of their fifth legs, which are transformed into flattened paddles and used for swimming purposes (White \& Sprito, 1973). Hence, the structures are known as swimming legs. The swimming legs confer on the crabs a power to dart at high speed through water bodies, while the dactyl bears thick setae along its edge. The chemoreceptive and feeding properties of the setae have been studied by different authors, however, there is no available data on the sensitivity of the setae in portunid crabs. This study investigated the chemo- and mechano-sensitivity of appendages and their involvement in feeding activities of the mud crab (Scylla paramamosain) using 
92 electrocardiography and behavioural assay. Both techniques were focused on the responses of the 93 mud crab to chemical and touch stimulus.

94

95

96

97

98

99

100

101

102

103

104

105

106

107

108

109

110

111

112

113

114

115

116

117

118

119

120

121

122

\section{MATERIALS \& METHODS}

\section{Crabs and holding condition}

A total of 20 female and male specimens of adult mud crab, $S$. paramamosain, $(9-11 \mathrm{~cm}$ in carapace width, $80-100 \mathrm{~g}$ in body weight) caught from the wild population were obtained from a local market, Kota Kinabalu, Sabah. They were stocked in a plastic tank $(122 \mathrm{~cm} \times 148.5 \mathrm{~cm}, 55$ $\mathrm{cm}$ high) filled with $55 \mathrm{~L}$ of seawater (30 cm deep) and placed in the roofed Shrimp Hatchery, Borneo Marine Research Institute, Universiti Malaysia Sabah. Half of the tank bottom was covered with $5 \mathrm{~cm}$ thick coral rubble to function as a biofilter substrate. Five pipes of polyvinyl chloride, $11 \mathrm{~cm}$ diameter and $20 \mathrm{~cm}$ long, were placed at the tank bottom as shelters for the crab. Tank water was aerated to ensure adequate oxygen level and the temperature, salinity, $\mathrm{pH}$, and concentration of dissolved oxygen ranged from 25.8 to $28.9^{\circ} \mathrm{C}, 19.47-20.05 \mathrm{ppt}, 6.89-7.29$, and 5.6-6.8 $\mathrm{mg} \mathrm{L}^{-}$

1, respectively. These parameters were measured using a $\mathrm{pH} / \mathrm{ORD} / \mathrm{EC} / \mathrm{DO}$ tester (Hanna Instruments, HI 9828, Washington, USA). The crabs were fed with fresh squid (Loligo sp.) in the morning and fish (Decapterus sp.) in the afternoon.

\section{Electrocardiography}

Three crabs (one male and two females) were used for the electrocardiography experiment. The specimens were excitable in response to the movement of the experimenter, so their eyes were painted with white nail polish to temporarily block their vision. The crabs were cold-anesthetised followed by drilling a small hole of about $0.5 \mathrm{~mm}$ diameter at each cardiac lobe of the carapace to expose the pericardial membrane. Two active electrodes (enamel-coated copper wire, $0.05 \mathrm{~mm}$ diameter) were implanted through the holes and glued with cyanoacrylate. Crab specimens with implanted electrodes were left for a day to recover in separate tanks with well-aerated seawater at a temperature $28^{\circ} \mathrm{C}, \mathrm{pH} 8.1$, and salinity $20 \mathrm{ppt}$.

21 To record the electrocardiogram (ECG), a test crab with two implanted electrodes was placed in a plastic test chamber $(17 \mathrm{~cm} \times 30 \mathrm{~cm} \times 9.5 \mathrm{~cm})$ filled with filtered seawater to $5 \mathrm{~cm}$ depth. The 
123 water level was enough to submerge the carapace. A third electrode was placed in the chamber as

124 a ground reference. The recording wires were of sufficient length to allow the freedom of 125 movement of the crab. However, the test specimens seldom moved during the ECG recordings.

126 The test chamber water was kept at a temperature of $28^{\circ} \mathrm{C}, \mathrm{pH}$ of 8.1 , and salinity of 20 ppt. The 127 ECG was linked to an amplifier (MEG-1200, Nihon Kohden, Tokyo, Japan) aligned to a digital 128 converter (FTT3P7PVB, ALS Controls, and Instruments, Nishinomiya, Japan), which converted 129 analogue signals to digital signals. The signals were then processed with EasyLogger software 130 (Easy SYNC Ltd., Glasgow, Scotland) and displayed on a laptop monitor. Stable ECGs were 131 obtained 15-30 min after the crab specimens were placed in the test chamber (Fig. 1). 132 Subsequently, a stimulus (touch or sugarcane juice) was applied to the appendages. The ECGs 133 were recorded during $25 \mathrm{~s}$ of stimulation.

134

\section{Stimuli}

136 Each appendage of the crab was stimulated thrice in two ways (touch and chemical). The 137 appendages were touched three times at intervals of 15-30 min with a hand-held micropipette 138 (heat-pulled glass capillary with a $50 \mu \mathrm{m}$ tip). For each crab, touch stimulation was conducted at 139 the swimming leg dactyls, walking leg dactyls, claws, antennae (tip and middle part), antennules 140 (lateral and medial flagella), and mouthpart (third maxilliped). Although the lateral and medial 141 flagella are close to each other and frequently in motion, it was possible to touch them with the 142 micropipette separately.

143

For the chemical stimulation, fresh sugarcane juice was selected because it contains 9.6-10.9\% sucrose and $0.22-0.33 \%$ glucose and fructose, which are more effective feeding stimulants than amino acids for the fiddler crab Uca pugilator (Robertson, Fudge \& Vermeer, 1981). The sugarcane juice measuring $0.1 \mathrm{~mL}$ (diluted to $50 \%$ or $10 \%$ with test chamber water, and filtered through paper Whatman No.1) was applied to the appendages by a hand-held Teflon pipette. Pipetting is one of the common methods to deliver a chemical solution to test crustaceans (Cericola \& Daniel, 2010; Aggio et al., 2012). During the chemical stimulation, the threshold concentration of the sugarcane juice at the mouthparts and walking legs were maintained to comply with previous reports. According to Liew et al. (2020), the threshold concentration of the sugarcane juice at the 
154 dispersion of the sugarcane juice around the appendages were conspicuous due to its greenish 155 colouration. Thereafter, the crab was removed and the test chamber was emptied. A control test 156 was performed by replacing the sugarcane juice with the tank water $(0.1 \mathrm{~mL})$ before the application 157 of the sugarcane juice, which was presented in triplicates.

158

To prevent the diffusion of the sugarcane juice from the antennule to the antennae, the

160

161

162

163

164

165

166

167

168

169

170

171

172

173

174

175

176

177

178

179

180

181

182

183

184 antennules were cauterised using an electric cauterizer (Gemini BC00314, Cellpoin Scientific, Gaithersburg, Germany) after applying the sugarcane juice. Thereafter, the sugarcane juice was applied to the antennae. For the cauterization, the crab was taken out of the test chamber, coldanesthetised, and gently held with a wet towel, and the tip of the cauterizer was touched on the distal segment bearing the outer and inner flagellum. After the cauterisation, the crab was placed back into the chamber and left for 20 to $30 \mathrm{~min}$ to recover to its stable and uniform ECG. The antennae were stimulated with $10 \%$ and $50 \%$ sugarcane juice. Each stimulation was delivered at an interval of 20-30 min to minimise residual responses to a previous stimulus and to avoid desensitization.

\section{Recording and measuring electrocardiograms}

Fifty-four stable ECGs were obtained from three test crabs: constant interbeat intervals (IBIs) of 0.5-0.8 s and constant amplitude of $0.3-0.4 \mathrm{mV}$. During the stimulus application, the ECGs were examined for the IBIs, measured to $0.1 \mathrm{~s}$. The first post-stimulus IBI was considered as the relevant response. The IBI values were normalised by logarithmic transformation (Nishi et al. 2004): normalised interval $=\log _{10}(T+1)$, where $T$ is the raw value of the IBI (s). Each test IBI was then compared with the mean pre-test IBI (the test-beat is out of the $95 \%$ confidence interval calculated using 10 pre-test IBIs).

\section{Behavioural bioassay}

During the stimulation at each appendage, the motion of other appendages was observed visually and combined with video recordings using CCD cameras with temporal resolutions of $0.017 \mathrm{~s}$, corresponding to 60 frames per second (Olympus Tough TG-3, Olympus Corporation, Tokyo, Japan). A total of 63 video recordings were analyzed, which were played back to examine the feeding behaviour on a computer screen. 
After the electrocardiography experiment, the feeding behaviour of each crab was observed in

187

188

189

190

191

192

193

194

195

196

197

198

199

200

201

202

203

204

205

206

207

208

209

210

211

\section{Behaviour change in response to stimuli}

213 Stimulation with the sugarcane juice elicited both the cardiac and feeding response of the crab.

the test chamber. The antennule was stimulated with a tweezered small piece of salted fish flesh (Decapterus sp.) (about $10 \mathrm{~mm} \times 5 \mathrm{~mm}, 2 \mathrm{~mm}$ thick) obtained from a local market. To stimulate the walking legs or swimming legs, a small piece of salted fish flesh was placed close to their dactyl. As described by Liew et al. (2020), the feeding behaviour in response to the stimulation was evaluated based on three appendage movements: (i) increase in antennular flicking rate, (ii) remarkable movement of the third maxillipeds, and (iii) probing the test chamber bottom with the claws. These behaviours were was visually observed, video-recorded, and a total of 30 video recordings were analyzed.

\section{RESULTS}

\section{Electrocardiography}

The electrocardiogram showed typical heartbeat response, slower heartbeat, or wider IBI of the crab, after the $10 \%$ or $50 \%$ sugarcane juice stimulation was presented to the swimming leg dactyl (Fig. 2A). However, no response was observed by mechanical touch stimulation (Fig. 2B). The crab with the antennules showed the heartbeat response, while those with the cauterised antennules showed no response to the stimulation by the sugarcane juice application given to the antennae. A statistically significant $(P<0.05)$ cardiac response to the sugarcane juice was recorded for the swimming legs, walking legs, claws, antennules (both the lateral and medial flagella), and mouthparts (Table 1). Regarding the touch test, statistically significant responses $(P<0.05)$ were observed for the walking legs, claws, antennae, and mouthparts of three specimens (Table 2). Both the lateral and medial flagella were not touch-sensitive. In the control test, the crab exhibited neither the cardiac response nor the feeding behaviour in response to tank water that was applied to all appendages.

During electrocardiography, the mud crab exhibited an increase in the antennule flicking rate, claw probing, and movement of the third maxillipeds. These responses occurred following the 
216 stimulation of the antennules and dactyls (both swimming and walking) with sugarcane juice. Such

217 feeding behaviour was not observed since the antennae were touch-sensitive (Table 2), but not

218 chemosensitive (Table 1). The touch stimulus alone did not elicit the feeding behaviour at all.

219

220

221

In response to a small piece of salted fish flesh placed on the swimming leg dactyl, the mud crab immediately exhibited movement of mouthpart appendages and kicked the flesh to the claw

222

223

224

225

226

227

228

229

230

231

232

233

234

235

236

237

238

239

240

241

242

243

244 245 under its body (Fig. 3). Other exhibited features include pushing the flesh to the walking leg dactyl and grabbing the piece with the claw to bring it to the mouth. There was a clear involvement of the swimming legs in feeding.

\section{DISCUSSION}

The present study reinstated the importance of swimming legs of the mud crab for swimming and its vital role in food detection. The dactyl of swimming legs was found to be chemosensitive and when the dactyl touched a piece of food, the food was quickly kicked forward under the body by the motion of swimming legs, grabbed by the claw, and ingested. The kicking motion was done without touch sensitivity. Among the legs in the mud crab, the swimming legs are farthest from the mouth, nevertheless, the motion of the swimming leg secures food grabbing by the claw.

Mud crab is a benthic predator, an opportunistic scavenger, and feeds on sessile or slowmoving benthic macroinvertebrates, mainly gastropods, crustaceans, and molluscs (AlbertsHubatsch et al., 2016). It also consumes fresh and decaying flesh of all kinds, hence, regarded as a detritivorous animal (Mamun et al., 2008; Nesakumari \& Thirunavukkarasu, 2014; Viswanathan \& Raffi, 2015; Paul et al., 2018). Previous studies have shown that S. serrata uses the dactyls of the walking legs by chemoreception to locate food (Alberts-Hubatsch et al., 2016). Besides, the flattened dactyls of the swimming legs might be more efficient than the pointed dactyls of the walking legs during food location. When crawling on the substrate, the dactyls of the swimming legs sweep the surface, which increases the likelihood of contacting scattered food items compared with the walking legs. Thus, the swimming legs of the mud crab are the most suited more appendage in locating food. 
246

247

248

249

250

251

252

253

254

255

256

257

258

259

260

261

262

263

264

265

266

267

268

269

270

271

272

273

274

275

276

The swimming legs are also used in burying behaviour (Parkes, Quinitio \& Vay, 2011). In aquaria, a pair of swimming legs are applied to flick sediment over the anterior of the carapace in S. serrata (Parkes, Quinitio \& Vay, 2011). To achieve this burying motion, the mud crab requires information about the quality of bottom sediment. Since the dactyl of the swimming legs is not touch-sensitive, the cue of the sediment quality might be mediated by the other mechanosensitive appendages such as the walking legs. According to Fedotov (2009), the hair receptors on chelipeds, antennas, and antennules in crayfish and other decapods are innervated by mechano- and chemoreceptor neurons and bimodal sensillae. In the present study, it was evident that the short antenna of the mud crab, unexpectedly, was touch-sensitive but not chemosensitive to food-related organic substances. In contrast, the antennae have been reported to be used mechanically in feed deposit and suspension in decapod crustaceans (Boxshall \& Jaume, 2013). This event suggests that the antennae are not directly involved in food detection. However, the potential role of the antennae in detecting the source of food odour is not ruled out. Weissburg (1994) reported that the blue crab could not orient the source of food odour in still water, but proceeded directly upstream toward the food odour source. Their findings indicated the importance of both rheotactic and chemical information for successful orientation.

Mechanoreceptors mediate remote perception of hydrodynamic signals such as disturbances in flow field caused by particles suspended in water columns or by the motions of live prey (Boxshall $\&$ Jaume, 2013). Assuming that the touch-sensitive antennae mediate hydrodynamic signals, the mud crab would be able to orient food odour source by olfaction aided by the perception of hydrodynamic signals by the antennae. The orientation may also be enhanced by the monomodal touch-sensitive sensillae reportedly present on the bristle patches on the carapace of Scylla spp. (Kawamura et al., In Press). The bristle patches are located behind the eyes in both males and females of four species of the mud crabs, and a touch stimulus given to the bristles is a mechanical signal for their courtship behaviour.

The antennule plays an important role in many behaviours of the mud crab, including locomotion, feeding, and mating (Boxshall \& Jaume, 2013). The lateral flagellum of the antennule bears bimodal sensilla, which are innervated by mechanoreceptor and chemoreceptor neurons in decapod crustaceans (Schmidt \& Mellon, 2011). The bimodal sensitivity of the antennule has been 
277 reported in several species of lobsters and shrimps. However, in the present study, the lateral

278 flagellum of the antennule of the mud crab is a unimodal chemosensor, distinctly chemosensitive,

279 but not touch-sensitive. van Weel \& Christofferson (1966) conducted an electrophysiological study 280 of appendages of two portunid crabs: Podpphthalmus vigil and Portunus sanguinolentus. In their 281 experiment, touch stimulation of walking legs, antennae, and mouthparts all caused the 282 electroactivity in the antennule. This is possibly due to the uncommon arrangement of a reference 283 electrode, which was inserted into the carapace and was not grounded. A reference electrode is 284 typically connected to a grounded electrode, which is essential for most electrophysiological 285 recordings. Therefore, the results of van Weel \& Christofferson (1966) are questionable so far as 286 this aspect is concerned. The present study revealed the bimodal sensitivity of the mouthparts, 287 claws, and walking legs of the mud crab, which seemed to be inconsistent with those of other 288 decapod crustaceans based on available literature findings.

289

290

291

292

293

294

295

296

297

298

299

300

301

302

303

304

305

306

\section{CONCLUSIONS}

Electrocardiography revealed that the thick setae along the edge of the swimming leg dactyl of the mud crab, Scylla paramamosain, were chemosensitive but not mechanosensitive, whereas the antennae were mechanosensitive but not chemosensitive. Behavioural observations showed the involvement of swimming legs in feeding. A combination of electrocardiographic and behavioural patterns of appendages indicated that the body parts directly involved in feeding include the mouthparts, claws, walking legs, swimming legs, and antennules.

\section{Ethical approval}

All experimental animals were cared for and handled following the guidelines suggested by the World Health Organization (WHO, Geneva, Switzerland), the Malaysian Code of Practice for the Care and Use of Animals for Scientific Purposes, and the Committee for the Update of the Guide for the Care and Use of Laboratory Animals, Institute of Laboratory Animal Research.

\section{Author Contributions}

Investigation and writing of original draft, Gunzo Kawamura; Investigation, Loke C. Keong; investigation, writing-review, editing, and correspondence, Leong-Seng Lim; funding acquisition 
307 and project administration, Annita S. Yong; language editing, Saleem Mustafa. All authors have 308 read and agreed to the published version of the manuscript.

309

310

311

312

313

314

315

316

317

318

319

320

321

322

323

324

325

326

327

328

329

330

331

332

333

334

335

336

\section{REFERENCES}

Ache BW. 1982. Chemoreception and thermoreception. In: Atwood HL \& Sandeman DC, eds. The biology of crustacean 3; Neurobiology: Structure and function. New York: Academic Press, 369-398.

Aggio JF, Tieu R, Wei A, Derby D. 2012. Oesophageal chemoreceptors of blue crab, Callinectes sapidus, sense chemical deterrents and can block ingestion of food. Journal of Experimental Biology 215:1700-1710 DOI: 10.1242/jeb.065854.

Alberts-Hubatsch H, Lee SY, Meynecke JO, Diele K, Nordhaus I, Wolff M. 2016. Life-history, movement, and habitat use of Scylla serrata (Decapoda: Portunidae): current knowledge and future challenges. Hydrobiologia 763:5-21.

Boxshall G, Jaume D. 2013. Antennules and antennae in the crustacea. In: Walting L \& Thiel M, eds. Oxford: Oxford University Press, 199-236.

Burnovicz A, Oliva D, Hermitte G. 2009. The cardiac response of the crab Chasmagnathus granulatus as an index of sensory perception. Journal of Experimental Biology 212:313-324 DOI: $10.1242 /$ jeb.022459.

Burnovicz A, Hermitte G. 2010 Conditioning of an autonomic response in Crustacea. Physiology \& Behavior 101:168-175 DOI: 10.1016/j.physbeh.2010.04.034.

Cericola VJ, Daniel PC. 2010. Chemically-mediated antennular grooming behavior and associated asymmetric setae: toward a hypothesis on their evolution in reptantian decapods. Journal of Crustacean Biology 30:557-570 DOI: 10.1651/09-3204.1.

Dunham DW, Oh JW. 1992. Chemical sex discrimination in the crayfish Procambarus clarkii: role of antennules. Journal of Chemical Ecology 18:2363-2372.

Fazhan H, Waiho K, Quinitio E, Baylon JC, Fujaya Y, Rukminasari N, Azri MFD, Shahreza MS, Ma H, Ikhwanuddin M. 2020. Morphological descriptions and morphometric discriminant 
337

338

339

340

341

342

343

344

345

346

347

348

349

350

351

352

353

354

355

356

357

358

359

360

361

362

363

364

365

366

367

function analysis reveal and additional four groups of Scylla spp. PeerJ 8:e8066 DOI: org/10.7717/peerj.8066.

Fedetov VP. 2009. Systems of chemoreception in decapod crayfish. Journal of Evolutional Biochemistry and Physiology 45:1-26.

Garm A. 2004a. Mechanical functions of setae from the mouth apparatus of seven species of decapod crustaceans. Journal of Morphology 260:85-100 DOI: 10.1002/jmor.10213.

Garm A. 2004b. Revising the definition of the crustacean seta an setal classification systems based on examinations of the mouthpart setae of seven species of decapods. Zoological Journal of the Linnean Society 142:233-252 DOI: 10.1111/j.1096-3642.2004.00132.x

Garm A, Høeg JT. 2000. Functional mouthpart morphology of the squat lobster Munida sarsi, with comparison to other anomurans. Marine Biology 137:123-138.

Garm A, Shabani S, Hoeg JT, Derby CD. 2005. Chemosensory neurons in the mouthparts of the spiny lobsters Panulirus argus and Panulirus interruptus (Crustacea: Decapoda). Journal of Experimental Marine Biology and Ecology 314:75-186 DOI: 10.1016/jembe.2004.08.016.

Gleeson RA, Adams MA, Smith AB. 1984. Characterization of a sex pheromone in the blue crab, Callinectes sapidus: crustecdysone studies. Journal of Chemical Ecology 10:913-921.

Gomez G, Atema J. 1996. Temporal resolution in olfaction: stimulus integration time of lobster chemoreceptor cells. Journal of Experimental Biology 199:1771-1779.

Grobel MS. 1990. Luminescent flash avoidance in the nocturnal crab Portunus xantusii. Journal of Experimental Biology 148:415-427.

Hermitte G, Maldonado H. 2006. Cardiovascular component of the context signal memory in the crab Chasmagnathus. Journal of Comparative Physiology 192:69-83 DOI: 10.1007/s00359005-0052-y.

Alberts-Hubatsch H, Lee S.Y., Meynecke JO, Diele K. 2016. Life-history, movement, and habitat use of Scylla serrata (Decapoda, Portunidae): current knowledge and future challenges. Hydrobiologia 763:5-21.

Ikhwanuddin M, Azmie G, Juariah HM, Zakaria MZ, Ambak MA. 2011. Biological information and population features of mud crab, Scylla from mangrove areas of Sarawak, Malaysia. Fisheries Research 108:299-306 DOI: 10.1016/j.fishres.2011.01.001

Jordão JM, Cronin TW, Oliveira RF. 2007. Spectral sensitivity of four species of fiddler crabs (Uca pugnax, Uca pugilator, Uca vomeris and Uca tangeri) measured by in situ 
368

369

370

371

372

373

374

375

376

377

378

379

380

381

382

383

384

385

386

387

388

389

390

391

392

393

394

395

396

397

398

microspectrophotometry. Journal of Experimental Biology A 210:447-453 DOI: 10.1242/jeb.12658.

Kamio M, Araki M, Nagayama T, Matsunaga S, Fusetani N. 2005. Behavioral and electrophysiological experiments suggest that the antennular outer flagellum is the site of pheromone reception in the male helmet crab Telmessus cheiragonus. Biological Bulletin 208:12-19.

Kawamura G. 1981. Recording of C-type of S potential from the retina of Sparidae. Bulletin of Japanese Society of Scientific Fisheries 47:825.

Kawamura G, Nakaizumi H, Motohiro T. 1992. Chemical perception and response of the Nile tilapia to geosmin. Water Science Technology 25:277-282 DOI: 10.2166/wst.1992.0062.

Kawamura G, Bagarinao TU, Cheah HS, Saito H, Yong ASK, Lim LS. 2020. Behavioural evidence for colour vision determined by conditioning in the purple mud crab Scylla tranquebarica. Fisheries Science 86: 299-305 DOI: 10.1007/s12562-019-01395-z.

Kawamura G, Bagarinao TU, Loke CK, Au HL, Lim LS, Yong ASK. 2021. Touch-sensitive bristles on the carapace of the mud crab Scylla paramamosain may be receptors for courtship signals. Fisheries Science 87:65-70 DOI: 10.1007/s12562-020-01478-2.

Keller TA, Powell I, Weissburg MJ. 2003. Role of olfactory appendages in chemically mediated orientation of blue crabs. Marine Ecology Progress Series 261:217-231.

Ketpadung R, Tangkrockolan NT. 2006. Changes in oxygen consumption and hear rate of the blue swimming crab, Portunus pelagicus (Linnaeus, 1766) following exposure to sublethal concentrations of copper. Journal of Environmental Biology 27:7-12.

Liew KS, Yong ASK, Lim L-S, Kawamura G. 2020. Dietary sugarcane juice as a feeding stimulant for the purple mud crab Scylla tranquebarica. Aquaculture Research 51:2164-2167 DOI: 10.1111/are.14545.

Mamun AA, Begum M, Mia MY, Alam MJ. 2008. Food and feeding habits of the mud crab Scylla serrata (Forskal) in Bangladesh. Journal of Bangladesh Society of Agriculture Science and Technology 5:141-144.

Medesani DA, Cervino CO, Ansaldo M, Rodriguez EM. 2011. Effect of parathion on cardiac rate, ventilatory frequency and hemolymphatic gas levels in the estuarine crab Neohelica granulata (Decapoda, Brachyura). Journal of Toxicology and Environmental Health Science 3:74-79 DOI: 10.1183/20734735.009817. 
399

400

401

402

403

404

405

406

407

408

409

410

411

412

413

414

415

416

417

418

419

420

421

422

423

424

425

426

427

428

Mellon DJr. 2012. Smelling, feeling, tasting and touching: behavioral and neural integration of antennular chemosensory and mechanosensory inputs in the crayfish. Journal of Experimental Biology 215:2163-2172 DOI: 10.1242/jeb.069492.

Mickel TJ, Childress JJ. 1982. Effects of pressure and temperature on the EKD and hear rate of the hydrothermal vent crab Bythograea thermydron (Brachyura). Biological Bulletin 162:7082.

Nesakumari CSA, Thirunavukkarasu N. 2014. Food and feeding behaviour of mud crab Scylla tranquebarica (Fabricius, 1798). Indian Journal of Veterinary \& Animal Science Research 43:229-235.

Nishi T, Kawamura G, Matsumoto K. 2004. Magnetic sense in the Japanese eel, Anguilla japonica, as determined by conditioning and electrocardiography. Journal of Experimental Biology 207:2965-2970 DOI: 10.242/jeb.01131.

Nishi T, Kawamura G. 2005. Anguilla japonica is already magnetosensitive at the glass eel phase. Journal of Fish Biology 67:1213-1224 DOI: 10.1111/j.1095-849.2005.00817.x.

Nishida S, Booth JD, Nemoto T, Kittaka J. 1990. Comparative morphology of the mouthparts and foregut of the final-stage phyllosoma, puerulus, and postpuerulus of the rock lobster Jasus edwardsii (Decapoda: Palinuridae). Journal of Crustacean Biology 10:293-305 DOI: $10.1163 / 193724090 \times 00104$.

Parkes L, Quinitio ET, Vay LL. 2011. Phenotypic differences between hatchery-reared and wild mud crabs, Scylla serrata, and the effects of conditioning. Aquaculture International 19:361380 .

Paul AK, Alam MM, Islam MS, Hussain M, Das SK. 2018. Feeding behaviour of mud crab Scylla serrata in north of Sundarbans, Bangladesh. AACL Bioflux 11:701-708.

Pearson WH, Olla BL. 1977. Chemoreception in the blue crab, Callinectes sapidus. Biological Bulletin 153:346-354.

Robertson JR, Fudge JA, Vermeer GK. 1981. Chemical and live feeding stimulants of the sand fiddler crab, Uca pugilator (Bosc). Journal of Experimental Marine Biology and Ecology 53:47-64 DOI: 10.1016/0022-0981(81)90083-6.

Sahlmann C, Chan TY, Chan BKK. 2011. Feeding models of deep-sea lobsters (Crustacea: Decapoda: Nephropidae and Palinuridae) in Northwest Pacific waters: Functional 
429

430

431

432

433

434

435

436

437

438

439

440

441

442

443

444

445

446

447

448

morphology of mouthparts, feeding behaviour and gut contents analysis. Zoologischer Anzeiger 250:55-66.

Schmidt M, Mellon DJr. 2011. Neural processing of chemical information in crustaceans. In:

Breithaupt T, Thiel M, eds. Chemical communication in crustaceans. New York: Springer, $123-147$.

Taylor EW, Leite CL, Cambell H, Intanai I, Wang T. 2007. Control of the heart in fish. In: Fernandes MN, Rantin FT, Glass ML, eds. Fish respiration and environment. Plymouth: Science Publisher, 341-375.

van Weel PB, Christofferson JP. 1966. Electrophysiological studies on perception in the antennulae of certain crabs. Physiological Zoology 39:317-325.

Viswanathan C, Raffi SM. 2015. The natural diet of the mud crab Scylla olivacea (Herbst, 1896) in Pichavaram mangroves, India. Saudi Journal of Biological Sciences 22:698-705.

Wall D, Paterson B, Mohan R. 2009. Behaviour of juvenile mud crabs Scylla serrata in aquaculture: Response to odours of moulting or injures crabs. Applied Animal Behaviour Science 121: 63-73. DOI: 10.1016/japplanim.2009.08.005

Weissburg MJ. 1994. Odour plumes and how blue crabs use them in finding prey. Journal of Experimental Biology 197:349-375.

White AQ, Sprito CP. 1973. Anatomy and physiology of the swimming leg musculature in the blue crab, Callinectes sapidus. Marine Behaviour and Physiology 2:141-153 DOI: $10.1080 / 10236247309386921$. 
Figure 1

Representation of the experimental set up used for recording the heart beat during the application of the different stimuli.

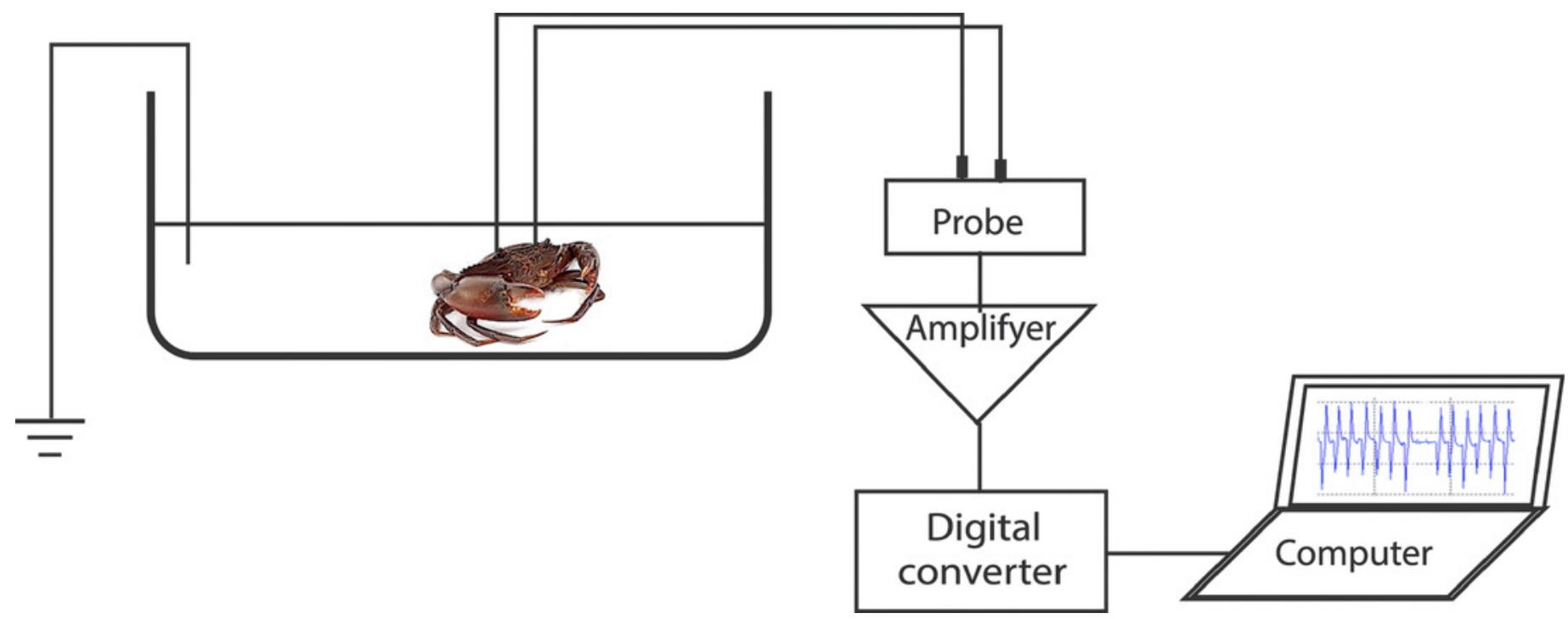


Figure 2

Typical electrocardiograms showing the heart beat response of Scylla paramamosain after the presentation of $50 \%$ sugarcane juice $(A)$ and no change in heart beat interval in response to a single touch stimulus (B) delivered to the swimming leg dactyl.

Arrows represent the application of the stimulus. 

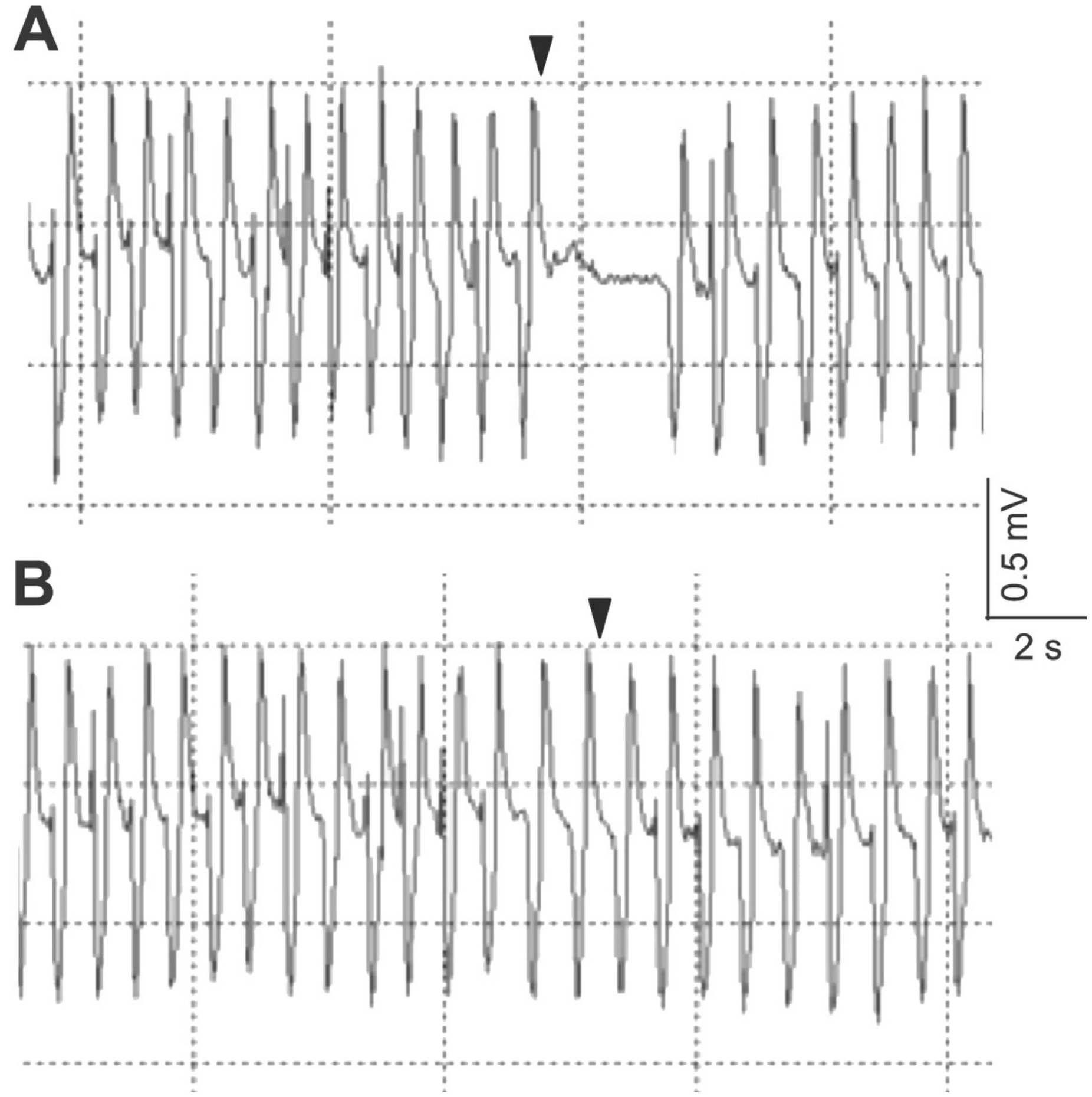


\section{Figure 3}

Sequential images of a food capture process with the swimming leg of Scylla paramamosain.

A, touching the dactyl of the swimming legs by a piece of fish flesh (arrow head); B, kicking the fish flesh under the body toward the mouth; $\mathrm{C}$, grabbing the fish flesh with a claw and conveying it to the mouth.
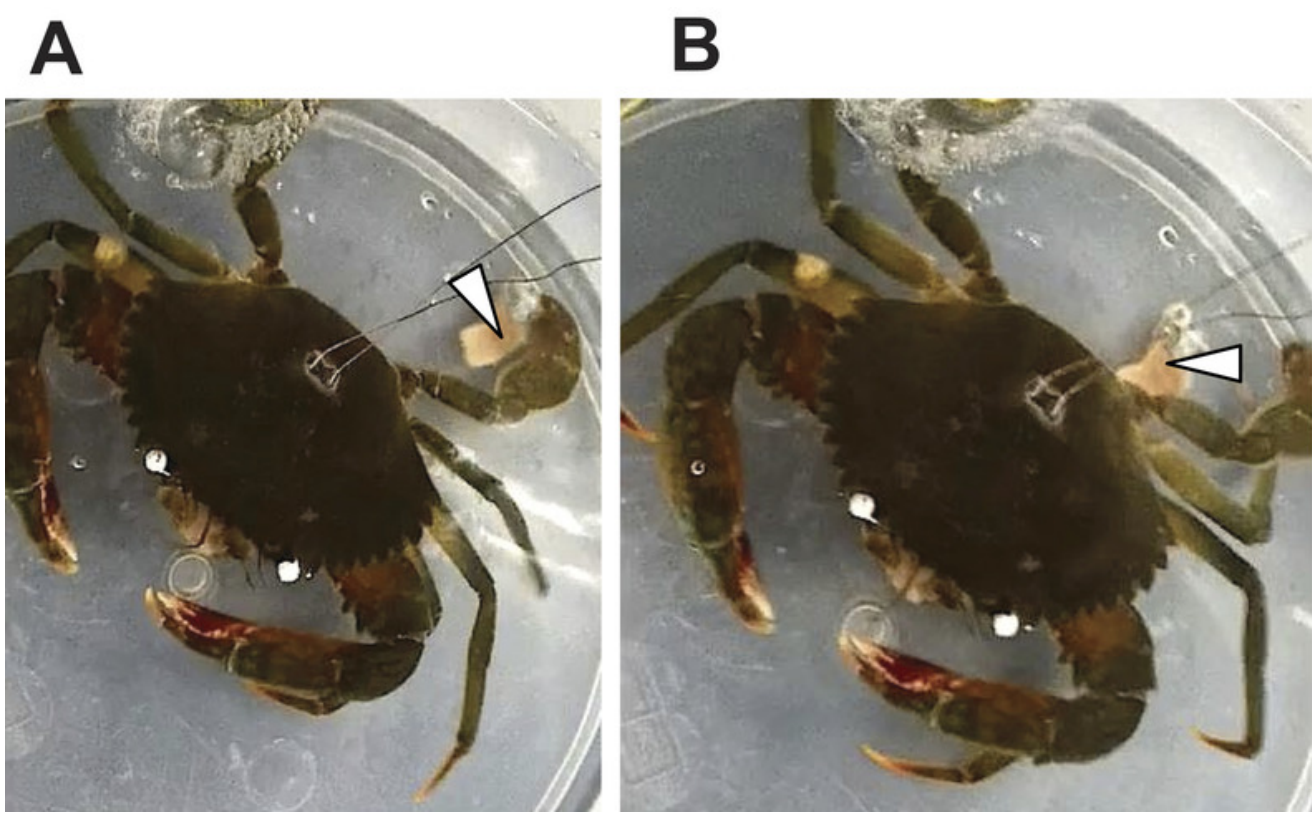

\section{C}

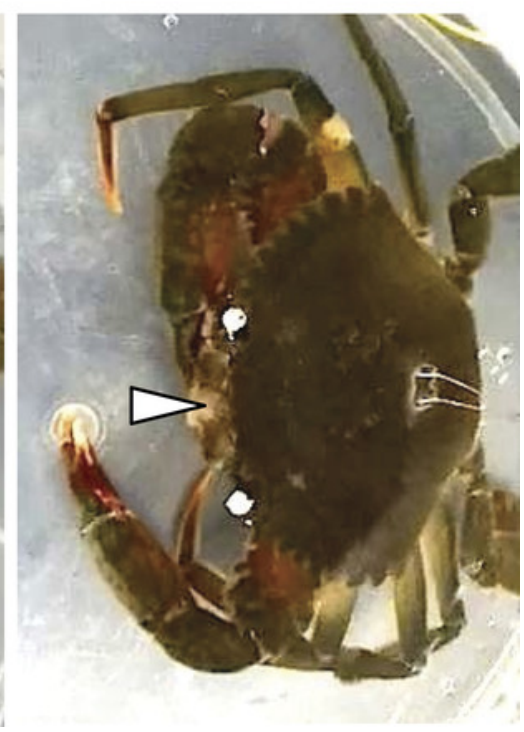




\section{Table $\mathbf{1}$ (on next page)}

Change in interbeat intervals (IBI) in Scylla paramamosain in response to sugarcane juice delivered to appendages.

The stimulation was triplicated but cardiac responses were shown only for the first single

touch. Mean pre-test IBI was calculated for 10 pre-test IBI. * denotes significantly larger testbeat interval than $95 \%$ confidence interval calculated using 10 pre-test IBIs. 


\begin{tabular}{|c|c|c|c|c|c|}
\hline Appendage & Crab & $\begin{array}{l}\text { Sugarcane juice } \\
\text { concentration }(\%)\end{array}$ & $\begin{array}{l}\text { Pre-test IBI: } \log 10- \\
\text { transformed mean IBI (s) }\end{array}$ & $\begin{array}{l}\text { Pre-test IBI: } \log 10- \\
\text { transformed IBI 95\% } \\
\text { confidence interval (s) }\end{array}$ & $\begin{array}{l}\text { Test-beat: } \log 10- \\
\text { transformed IBI (s) }\end{array}$ \\
\hline \multirow[t]{6}{*}{ Swimming leg } & \multirow{2}{*}{ A (male) } & 10 & 0.248 & $0.171-0.325$ & $0.646^{*}$ \\
\hline & & 50 & 0.237 & $0.169-0.305$ & $0.898^{*}$ \\
\hline & \multirow{2}{*}{ B (female) } & 10 & 0.290 & $0.249-0.331$ & $0.643 *$ \\
\hline & & 50 & 0.266 & $0.233-0.299$ & $0.981 *$ \\
\hline & \multirow{2}{*}{$\mathrm{C}$ (female) } & 10 & 0.237 & $0.207-0.267$ & $0.620^{*}$ \\
\hline & & 50 & 0.247 & $0.202-0.292$ & $0.929 *$ \\
\hline \multirow[t]{6}{*}{ Walking leg } & \multirow{2}{*}{ A } & 10 & 0.404 & $0.350-0.458$ & $0.737 *$ \\
\hline & & 50 & 0.261 & $0.206-0.316$ & $0.729 *$ \\
\hline & \multirow{2}{*}{ B } & 10 & 0.331 & $0.261-0.401$ & $0.659 *$ \\
\hline & & 50 & 0.246 & $0.178-0.314$ & $0.676^{*}$ \\
\hline & \multirow{2}{*}{$\mathrm{C}$} & 10 & 0.400 & $0.354-0.446$ & $0.898^{*}$ \\
\hline & & 50 & 0.203 & $0.168-0.238$ & $0.484 *$ \\
\hline \multirow[t]{6}{*}{ Claw } & \multirow{2}{*}{$\mathrm{A}$} & 10 & 0.273 & $0.223-0.313$ & $0.979 *$ \\
\hline & & 50 & 0.243 & $0.196-0.290$ & $0.587 *$ \\
\hline & \multirow{2}{*}{$\mathrm{B}$} & 10 & 0.250 & $0.204-0.296$ & $0.754 *$ \\
\hline & & 50 & 0.276 & $0.234-0.318$ & $1.157^{*}$ \\
\hline & \multirow{2}{*}{$\mathrm{C}$} & 10 & 0.261 & $0.194-0.328$ & $0.618^{*}$ \\
\hline & & 50 & 0.285 & $0.109-0.461$ & $0.771 *$ \\
\hline \multirow[t]{4}{*}{ Antenna } & \multirow{2}{*}{ A } & 10 & 0.216 & $0.188-0.244$ & 0.236 \\
\hline & & 50 & 0.137 & $0.066-0.208$ & 0.090 \\
\hline & \multirow{2}{*}{ B } & 10 & 0.180 & $0.150-0.210$ & 0.207 \\
\hline & & 50 & 0.089 & $0.020-0.158$ & 0.117 \\
\hline
\end{tabular}




\begin{tabular}{|c|c|c|c|c|c|}
\hline & $C$ & 10 & 0.246 & $0.206-0.286$ & 0.217 \\
\hline & $c$ & 50 & 0.198 & $0.127-0.269$ & 0.196 \\
\hline \multirow[t]{6}{*}{ Antennule } & \multirow{2}{*}{ A } & 10 & 0.223 & $0.169-0.277$ & $0.633^{*}$ \\
\hline & & 50 & 0.284 & $0.241-0.327$ & $0.844^{*}$ \\
\hline & \multirow{2}{*}{ B } & 10 & 0.187 & $0.136-0.238$ & $0.375^{*}$ \\
\hline & & 50 & 0.253 & $0.201-0.305$ & $0.832 *$ \\
\hline & \multirow{2}{*}{$\mathrm{C}$} & 10 & 0.255 & $0.173-0.337$ & $0.862 *$ \\
\hline & & 50 & 0.180 & $0.144-0.216$ & $1.097^{*}$ \\
\hline \multirow[t]{6}{*}{ Mouthparts } & \multirow{2}{*}{ A } & 10 & 0.308 & $0.261-0.355$ & $0.671^{*}$ \\
\hline & & 50 & 0.339 & $0.307-0.371$ & $0.969^{*}$ \\
\hline & \multirow{2}{*}{ B } & 10 & 0.301 & $0.265-0.337$ & $0.746^{*}$ \\
\hline & & 50 & 0.306 & $0.285-0.327$ & $0.859^{*}$ \\
\hline & \multirow{2}{*}{$\mathrm{C}$} & 10 & 0.277 & $0.224-0.310$ & $0.633^{*}$ \\
\hline & & 50 & 0.339 & $0.280-0.398$ & $0.754 *$ \\
\hline
\end{tabular}




\section{Table 2 (on next page)}

Change in interbeat intervals (IBI) in Scylla paramamosain in response to touch stimulus delivered to appendages .

The stimulation was triplicated but cardiac responses were shown only for the first single touch. Mean pre-test IBI was calculated for 10 pre-test IBI. * denotes significantly larger testbeat interval than $95 \%$ confidence interval calculated using 10 pre-test IBIs. 


\begin{tabular}{ccccc}
\hline Appendage & Crab & $\begin{array}{c}\text { Pre-test IBI: log10- } \\
\text { transformed mean IBI } \\
(\mathrm{s})\end{array}$ & $\begin{array}{c}\text { Pre-test beat: log10- } \\
\text { transformed IBI 95\% } \\
\text { confidence interval (s) }\end{array}$ & $\begin{array}{c}\text { Test-beat: log10- } \\
\text { transformed IBI (s) }\end{array}$ \\
\hline Swimming leg & A (male) & 0.139 & $0.063-0.215$ & 0.097 \\
& B (female) & 0.170 & $0.125-0.215$ & 0.146 \\
& C (female) & 0.210 & $0.181-0.239$ & 0.193 \\
\hline Walking leg & $\mathrm{A}$ & 0.337 & $0.287-0.387$ & $0.782^{*}$ \\
& $\mathrm{~B}$ & 0.307 & $0.237-0.377$ & $0.646^{*}$ \\
& $\mathrm{C}$ & 0.329 & $0.287-0.371$ & $0.868^{*}$ \\
\hline Claw & $\mathrm{A}$ & 0.323 & $0.264-0.382$ & $0.627^{*}$ \\
& $\mathrm{~B}$ & 0.330 & $0.316-0.344$ & $0.658^{*}$ \\
& $\mathrm{C}$ & 0.359 & $0.326-0.392$ & $0.718^{*}$ \\
\hline Antenna & $\mathrm{A}$ & 0.226 & $0.163-0.289$ & $0.679^{*}$ \\
& $\mathrm{~B}$ & 0.244 & $0.219-0.269$ & $0.668^{*}$ \\
& $\mathrm{C}$ & 0.245 & $0.213-0.277$ & $0.765^{*}$ \\
\hline Antennule & $\mathrm{A}$ & 0.139 & $0.063-0.215$ & 0.124 \\
& $\mathrm{~B}$ & 0.244 & $0.197-0.251$ & 0.220 \\
& $\mathrm{C}$ & 0.184 & $0.115-0.253$ & 0.225 \\
\hline Mouthparts & $\mathrm{A}$ & 0.251 & $0.205-0.297$ & $0.684^{*}$ \\
& $\mathrm{~B}$ & 0.319 & $0.289-0.349$ & $0.647^{*}$ \\
& $\mathrm{C}$ & 0.154 & $0.126-0.182$ & $0.563^{*}$ \\
\hline
\end{tabular}

